\title{
PENGARUH BUKU SAKU GIZI TERHADAP TINGKAT PENGETAHUAN GIZI PADA ANAK KELAS 5 MUHAMMADIYAH DADAPAN DESA WONOKERTO KECAMATAN TURI KABUPATEN SLEMAN YOGYAKARTA
}

\author{
Desy Eliana, Solikhah \\ Fakultas Kesehatan Masyarakat, Universitas Ahmad Dahlan, Yogyakarta
}

\begin{abstract}
Background :Nutrition education is very important given since entering primary school for children have good nutrition knowledge level. The level of nutrition knowledge a person will influence the attitudes and behavior in selecting foods that will ultimately affect the nutritional state of the individual concerned. Nutrition pocket book is one of the methods of health education in the form of print media that can provide information about nutrition and to increase nutrition knowledge in children, with increased knowledge of nutrition is expected to prevent diseases caused by malnutrition. This study aims to determine the effect of nutrition on the pocket book on child nutrition knowledge level of grade 5 elementary school Muhammadiyah Dadapan Village District Wonokerto Turi Sleman Yogyakarta

Method: Type of research is quasi Exsperiment with pre test and post test one group design. The samples were grade 5 students Muhammadiyah Dadapan Village Elementary School District Wonokerto Turi Sleman Yogyakarta, which numbered 30 students, using primary data. Measurement of knowledge conducted using questionnaires before and after the pocket book. Data analysis using Paired Sample T-Test

Results: There is increased knowledge about nutrition in children 5th grade elementary school Muhammadiyah Dadapan Village District Wonokerto Turi Sleman Yogyakarta with an average value, it is known that the mean value before it is given a pocket book and the mean is given after each pocket book for 71.33 and 91.07 . Mean shows the average difference before and after the administration of a paperback book. Significant value Sig (2-tailed) $(0.000)<0025$ and $95 \%$ Confidence interval $-22.820<1>-16.646$ (does not include item 1). The probability or possibility of true hypotheses is small so $\mathrm{Ho}$ is rejected, it states that there is a difference of mean between before and after given a pocket book, pocket book on nutrition so that gives the effect of nutrition knowledge of elementary school children grades 5 Muhammadiyah Dadapan Wonokerto In the village of Turi Sleman District, Yogyakarta.

Conclusion: The Pocket Book of Nutrition have a significant influence on the increased knowledge of nutrition in children 5th grade elementary school Muhammadiyah Village Dadapan Wonokerto Turi Sleman District, Yogyakarta.
\end{abstract}

Keywords: pocket book of nutrition, Nutrition Knowledge Levels, Nutrition in Children

\section{PENDAHULUAN}

Gizi merupakan bagian yang cukup penting dalam mewujudkan sumber daya manusia yang berkualitas. Untuk mencapai keseimbangan konsumsi gizi pada setiap individu atau keluarga juga dipengaruhi banyak faktor, seperti ekonomi sosial budaya, kebiasaan, kesukaan, kondisi kesehatan termasuk juga pendidikan dan pengetahuan seputar masalah gizi.

Menurut MDG's tahun 2007 secara umum status gizi penduduk semakin membaik. Terlihat dari indikator persentase penderita gizi kurang dan gizi buruk yang menurun dari $37,47 \%$ pada tahun 1989 menjadi $26,36 \%$ pada tahun 1999 . Indikator status gizi ini terus membaik menjadi 27,3\% pada tahun 2002 namun meningkat kembali menjadi $28,17 \%$ pada tahun 2005 . Jika menggunakan keadaan tahun 1989 sebagai dasar, Indonesia diharapkan dapat mencapai target 18,74\% pada tahun 2015 (MDG's, 2007). Hasil laporan kasus Gizi yang terjadi di Wilayah 
Desa Wonokerto Kecamatan Turi Kabupaten Sleman Yogyakarta sampai bulan 7 September 2010 disebutkan bahwa :

\begin{tabular}{|c|c|c|c|c|c|c|c|c|}
\hline \multirow{3}{*}{ Aktivitas Fisik } & \multicolumn{4}{|c|}{ Status Gizi } & \multirow{2}{*}{\multicolumn{2}{|c|}{ Total }} & \multirow{3}{*}{$\begin{array}{c}\mathrm{P} \\
\text { value }\end{array}$} & \multirow{3}{*}{$\begin{array}{c}\text { RP } \\
(95 \% \\
\mathrm{Cl})\end{array}$} \\
\hline & \multicolumn{2}{|c|}{ Tidak baik } & \multicolumn{2}{|c|}{ Baik } & & & & \\
\hline & $\mathrm{N}$ & $\%$ & $\mathrm{~N}$ & $\%$ & $\mathrm{~N}$ & $\%$ & & \\
\hline $\begin{array}{l}\text { Tidak berolah- } \\
\text { raga }\end{array}$ & 10 & 30,3 & 6 & 30,0 & 16 & 30,2 & 0.981 & $\begin{array}{r}1,005 \\
0638\end{array}$ \\
\hline Berolahraga & 23 & 69,7 & 14 & 70,0 & 37 & 69,8 & & $1,585)$ \\
\hline Total & 33 & $\begin{array}{c}100, \\
0\end{array}$ & 20 & $\overline{100,0}$ & 53 & 100,0 & & \\
\hline
\end{tabular}

\section{METODE PENELITIAN}

\section{A. Jenis Penelitian}

Jenis penelitian ini adalah quasi experiment atau eksperimental semu dengan rancangan pra dan pasca intervensi. Pada rancangan ini perubahan yang terjadi setelah intervensi dicatat dan dibandingkan dengan keadaan sebelumnya.

\section{B. Kerangka Penelitian}

Input

Buku

Saku Gizi
Proses

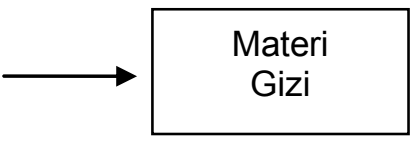

Output

Tingkat Pengetahuan Gizi Pada Anak Sekolah Dasar Kelas 5

Gambar 1. Kerangka Konsep Penelitian

\section{Teknik Pengumpulan dan Analisis Data}

1) Pelaksanaan penelitian diawali dengan perkenalan kemudian pembagian kuesioner yang telah disiapkan (pre test). Sebelum kuesioner dibagikan, siswa terlebih dahulu diberikan penjelasan mengenai tata cara pengisian kuesioner. Penelitian dilanjutkan dengan pemberian buku saku gizi. Pelaksanaan post test dilakukan 3 hari setelah pre test, yaitu pada hari Kamis 21 April 2011. Kegiatan dilakukan sebagaimana pelaksanaan pre test yaitu dengan membagikan kuesioner serupa.

2) Populasi dan Sampel

Populasi dalam penelitian ini adalah anak kelas 5 SD muhammadiyah Dadapan Desa Wonokerto Kecamatan Turi Kabupaten Sleman Yogyakarta, dengan alasan bahwa pada siswa Sekolah Dasar Kelas 5 sudah memenuhi kriteria penelitian karena siswa kelas 5 SD sudah dapat membaca dengan baik dan benar, serta mereka dapat memahami isi dari buku saku tersebut. Sampel dalam peneltian ini sama dengan populasi yaitu anak kelas 5 SD Muhammadiyah Dadapan di Desa Wonokerto Kecamatan Turi Kabupaten Sleman. Teknik pengambilan sampel pada penelitian ini adalah 
total sampel. Jumlah sampel dalam penelitian ini adalah 30 anak. Terdiri dari jumlah laki laki 11 orang dan jumlah perempuan 19 orang.

3) Analisis Data

Hasil pengukuran variabel yang diteliti akan dikumpulkan dan diolah untuk disajikan dalam bentuk tabel dan paparan. Kemudian dilakukan analisis dengan Uji Paired Sample T-test. Analisis data dilakukan dengan menggunakan bantuan program SPSS dengan tingkat kepercayaan $95 \%$ dan $\alpha 0,05$.

\section{HASIL PENELITIAN DAN PEMBAHASAN}

\section{A. Hasil Penelitian}

\section{1) Karakteristik Responden}

a) Distribusi Responden Menurut Usia Siswa kelas 5 SD Muhammadiyah Dadapan

Berdasarkan hasil wawancara yang telah dilakukan, maka distribusi responden menurut usia dapat disajikan pada tabel 2 .

Tabel 2. Distribusi Responden Berdasarkan Usia Siswa Kelas 5 di SD Muhammadiyah Dadapan Tahun 2011

\begin{tabular}{cccc}
\hline \multirow{2}{*}{ No } & \multirow{2}{*}{ Umur (tahun) } & \multicolumn{2}{c}{ Responden } \\
\cline { 3 - 4 } & & Jumlah & Persentase \\
\hline 1 & 9 & 1 & $3,3 \%$ \\
\hline 2 & 10 & 8 & $26,7 \%$ \\
\hline 3 & 11 & 15 & $50 \%$ \\
\hline 4 & 12 & 4 & $13,3 \%$ \\
\hline 5 & 13 & 2 & $6,7 \%$ \\
\hline \multicolumn{2}{c}{ Jumlah } & 30 & $100 \%$ \\
\hline
\end{tabular}

Tabel 2 menunjukkan bahwa responden pada umur 11 tahun merupakan proporsi tertinggi (50\%) dan 9 tahun merupakan kelompok proporsi terendah $(3,3 \%)$.

b) Distribusi Responden Berdasarkan Jenis Kelamin

Berdasarkan hasil kuesioner yang dibagikan sebelum intervensi, distribusi responden berdasarkan jenis kelamin dapat disajikan pada tabel 3 sebagai berikut

Tabel 3. Distribusi Responden Berdasarkan Jenis Kelamin Di SD Muhammadiyah Dadapan Desa Wonokerto

\begin{tabular}{cccc}
\hline \multirow{2}{*}{ No } & \multirow{2}{*}{ Jenis Kelamin } & \multicolumn{2}{c}{ Sampel } \\
\cline { 3 - 4 } & Laki laki & Jumlah & Persentase \\
\hline 1 & 18 & $60 \%$ \\
\hline 2 & Perempuan & 12 & $40 \%$ \\
\hline & Jumlah & 30 & $100 \%$ \\
\hline
\end{tabular}


Tabel 3 menunjukkan bahwa responden yang berjenis kelamin lakilaki memiliki proporsi tertinggi (60\%) atau 18 responden dan responden berjenis kelamin perempuan adalah $(40 \%)$ atau 12 responden.

c) Distribusi Responden Berdasarkan Pernah Atau Tidaknya Mendapatkan Informasi Tentang Gizi Sebelum Diberikan Buku Saku

Berdasarkan hasil kuesioner yang telah diberikan sebelum intervensi, maka distribusi frekuensi responden menurut pernah atau tidaknya mendapatkan informasi tentang gizi sebelum diberikan buku saku disajikan pada tabel 4 sebagai berikut :

Tabel 4. Distribusi Responden Berdasarkan Tingkat Pengetahuan Gizi Siswa SD Muhammadiyah Dadapan Desa Wonokerto

\begin{tabular}{|c|c|c|c|}
\hline \multirow{2}{*}{ No } & \multirow{2}{*}{$\begin{array}{c}\text { Pengetahuan siswa } \\
\text { sebelumnya }\end{array}$} & \multicolumn{2}{|c|}{ Frekuensi } \\
\hline & & Jumlah orang & Persentase \\
\hline 1 & Pernah & 30 & $100 \%$ \\
\hline 2 & Belum pernah & 0 & $0 \%$ \\
\hline & Jumlah & 30 & $100 \%$ \\
\hline
\end{tabular}

Distribusi responden menurut pengetahuan sebelumnya dibedakan menjadi dua kategori yaitu pernah mendapatkan informasi terkait tentang gizi dan tidak pernah mendapatkan informasi terkait gizi. Berdasarkan tabel dapat diketahui bahwasanya semua siswa pernah memperoleh informasi terkait tentang gizi pada anak sebelumnya.

d) Distribusi Responden Berdasarkan Sumber Informasi Gizi Yang Diperoleh Siswa

Berdasarkan hasil kuesioner yang telah diberikan sebelum intervensi, maka distribusi frekuensi responden menurut sumber informasi disajikan pada tabel 5 sebagai berikut :

Tabel 5. Distribusi Responden Berdasarkan Sumber Informasi yang Diperoleh Siswa SD Muhammadiyah Dadapan Desa Wonokerto.

\begin{tabular}{llcc}
\hline \multirow{2}{*}{ No } & \multirow{2}{*}{ Sumber informasi } & \multicolumn{2}{c}{ Frekuensi } \\
\cline { 3 - 4 } & & Jumlah orang & Persentase \\
\hline 1 & Saudara /orang tua / keluarga & 2 & $6,7 \%$ \\
\hline 2 & Teman / sahabat & 2 & $6,7 \%$ \\
\hline 3 & Guru & 19 & $63,3 \%$ \\
\hline 4 & Surat kabar / majalah / buku & 0 & $0 \%$ \\
\hline 5 & Radio/ televisi & 1 & $3,3 \%$ \\
\hline 6 & Internet & 3 & $10 \%$ \\
\hline 7 & Petugas kesehatan & 3 & $10 \%$ \\
\hline & Jumlah & 30 & $100 \%$ \\
\hline
\end{tabular}


Tabel 5 menunjukkan bahwa responden yang mendapatkan informasi tentang gizi dari guru memiliki proporsi yang lebih tinggi $(63,3 \%)$ dari saudara/orang tua/keluarga $(6,7 \%)$, dari teman/sahabat $(6,7 \%)$ dan melalui radio/telivisi sebanyak $(3,3 \%)$ adapun sisanya mendapat informasi tentang gizi melalui internet sebanyak $(10 \%)$,saudara dan petugas kesehatan (10\%).

\section{e) Distribusi Responden Berdasarkan Tingkat Pendidikan Ibu}

Berdasarkan hasil kuesioner yang telah diberikan sebelum intervensi, maka distribusi responden berdasarkan tingkat pendidikan ibu dapat disajikan pada tabel 6 berikut ini :

Tabel 6. Distribusi Responden Berdasarkan Tingkat Pendidikan Ibu/ Orang Tua Wali di SD Muhammadiyah Dadapan Desa Wonokerto

\begin{tabular}{clcc}
\hline \multirow{2}{*}{ No } & \multirow{2}{*}{ Tingkat Pendidikan Ibu } & \multicolumn{2}{c}{ Frekuensi } \\
\cline { 3 - 4 } & & Jumlah orang & Persentase (\%) \\
\hline 1 & Tidak tamat SD & 5 & $16,7 \%$ \\
\hline 2 & SD & 0 & $0 \%$ \\
\hline 3 & SMP/sederajat & 5 & $16,7 \%$ \\
\hline 4 & SMU/sederajat & 19 & $63,3 \%$ \\
\hline 5 & Akademi/sarjana & 1 & $3,3 \%$ \\
\hline & Jumlah & 30 & $100 \%$ \\
\hline
\end{tabular}

Tabel 6 menunjukkan bahwa responden dengan tingkat pendidikan ibu/orang tua wali SMU/sederajat memiliki proporsi tertinggi $(63,3 \%)$ dan responden yang memiliki tingkat pendidikan ibu terendah yaitu akademi/sarjana dengan proporsi $(3,3 \%)$.

\section{f) Distribusi Responden Berdasarkan Tingkat Pendidikan Ayah}

Berdasarkan hasil kuesioner yang telah dibagikan kepada responden, maka distribusi responden berdasarkan tigkat pendidikan ayah dapat disajikan pada tabel 8 berikut ini :

Tabel 7. Distribusi Responden Berdasarkan Tingkat Pendidikan Ayah/ Orang Tua Wali di SD Muhammadiyah Dadapan Desa Wonokerto

\begin{tabular}{|c|c|c|c|}
\hline \multirow{2}{*}{ No } & \multirow{2}{*}{$\begin{array}{c}\text { Tingkat Pendidikan } \\
\text { Ayah }\end{array}$} & \multicolumn{2}{|c|}{ Frekuensi } \\
\hline & & Jumlah orang & Persentase (\%) \\
\hline 1 & Tidak tamat SD & 4 & $13,3 \%$ \\
\hline 2 & SD & 3 & $10 \%$ \\
\hline 3 & SMP/sederajat & 0 & $0 \%$ \\
\hline 4 & SMU/sederajat & 17 & $56,7 \%$ \\
\hline 5 & Akademi/sarjana & 6 & $20 \%$ \\
\hline & Jumlah & 30 & $100 \%$ \\
\hline
\end{tabular}


Tabel 7 menunjukkan bahwa responden dengan tingkat pendidikan SMU/Sederajat memiliki proporsi tertinggi $(56,7 \%)$ dan responden yang memiliki tingkat pendidikan ayah SD terendah dengan proporsi $(10 \%)$.

\section{2) Analisis Univariat}

a) Distribusi Responden Menurut Tingkat Pengetahuan Gizi Siswa Sebelum Diberikan Buku Saku

Tabel 8. Distribusi Frekuensi Responden Menurut Tingkat Pengetahuan Gizi

Sebelum Diberikan Buku Saku (Pre Test)

\begin{tabular}{ccc}
\hline Tingkat pengetahuan & Jumlah & persentase \\
\hline Baik & 18 & $60 \%$ \\
\hline Kurang baik & 12 & $40 \%$ \\
\hline Jumlah & 30 & $100 \%$ \\
\hline
\end{tabular}

Pada tabel 8 terlihat bahwasanya responden yang menjadi sampel dalam penelitian memiliki pengetahuan gizi yang baik sebelum diberikan buku saku. Hal ini dikarenakan dari 30 responden lebih dari $50 \%$ anak yang memiliki tingkat pengetahuan gizi yang baik yaitu 18 siswa masuk kedalam kategori pengetahuan yang baik (60\%). Adapun selebihnya masuk kedalam kategori pengetahuan siswa yang kurang baik dengan jumlah siswa 12 orang $(40 \%)$.

b) Distribusi Frekuensi Responden Menurut Pengetahuan Gizi Sesudah Diberikan Buku Saku (Post Test)

Tabel 9. Distribusi Frekuensi Responden Menurut Pengetahuan Gizi Sesudah Diberikan Buku Saku (Post Test)

\begin{tabular}{ccc}
\hline Tingkat pengetahuan & Jumlah & persentase \\
\hline Baik & 30 & $100 \%$ \\
\hline Kurang baik & 0 & $0 \%$ \\
\hline Jumlah & 30 Orang & $100 \%$ \\
\hline
\end{tabular}

Pada saat sebelum diberikan buku saku gizi responden yang memiliki tingkat pengetahuan gizi baik lebih dari 50\%. Setelah responden diberikan intervensi berupa buku saku, maka jumlah siswa yang berpengetahuan baik meningkat menjadi 30 orang (100\%). Tidak ada siswa yang memiliki pengetahuan gizi kurang baik.

\section{3) Analisis Bivariat}

Analisis yang digunakan dalam penelitian ini adalah Paired Sample $T$ test dengan taraf signifikan $5 \%$. Analisis ini bertujuan untuk melihat ada tidaknya perbedaan pada populasi yang diamati dua kali. Perbedaan yang diamati pada penelitian ini adalah perbedaan pengetahuan siswa SD 
Muhammadiyah Dadapan dengan melakukan pengamatan yaitu sebelum diberikan buku saku dan sesudah diberikan buku saku.

\begin{tabular}{|c|c|c|c|c|c|c|c|c|}
\hline \multicolumn{9}{|c|}{ Tabel 10. Hasil Uji Paired Samples T-Test } \\
\hline
\end{tabular}

Berdasarkan hasil, diketahui bahwa nilai mean sebelum diberikan buku saku dan mean sesudah diberikan buku saku sebesar - 19,733. Maka kemaknaan secara statistiknya menunjukkan bahwasanya ada perbedaan antara pengetahuan sebelum dengan sesudah diberikan buku saku, Nilai Signifikan Sig (2-tailed) (0.000) < 0.025 dan Confidence interval $95 \%$ $22,820<1>-16,646$ (tidak mencakup angka 1). Probabilitas atau kemungkinan hipotesis benar adalah kecil sehingga Ho ditolak, ini menyatakan bahwa ada perbedaan rerata antara sebelum dengan sesudah diberikan buku saku, sehingga buku saku Gizi memberikan pengaruh terhadap pengetahuan gizi anak kelas 5 SD Muhammadiyah Dadapan Di Desa Wonokerto Kecamatan Turi Kabupaten Sleman Yogyakarta.

\section{B. PEMBAHASAN}

1) Tingkat Pengetahuan Gizi Siswa Kelas 5 SD Muhammadiyah Dadapan Sebelum Diberikan Buku Saku

Tingkat pengetahuan seseorang sangat dipengaruhi oleh informasi yang didapat responden sebelumnya. Pada saat pre test dilakukan hasil yang diperoleh menunjukkan bahwa siswa sebelum diberikan buku saku memiliki pengetahuan gizi yang baik sebanyak 18 orang, hal ini mengingat semua responden $(100 \%)$ menyatakan pernah mendapat informasi yang terkait dengan gizi seimbang dari berbagai sumber. Informasi yang telah didapatkan siswa sebelumnya menjadikan siswa memiliki pengetahuan yang baik terkait dengan gizi. Macam sumber informasi yaitu media cetak (buku, majalah, surat kabar, novel, leaflet, bokklet, poster, dll), media elektronik (internet, TV, radio, video, slide, film, dll), bill board (Notoadmodjo, 2003) atau dapat juga guru, orang tua, dan petugas pelayanan kesehatan. Syafinah Wahyu (2010), pernah meneliti tentang pengaruh buku saku sebagai media konsultasi gizi terhadap penurunan kadar gula darah anggota persadia RSUD Kota Yogyakarta. Hasilnya buku saku tidak memberikan pengaruh terhadap tingkat pengetahuan penderita Diabetes Melitus didalam Pengelolaan Diabetes Mellitus, hal tersebut diakibatkan karena penderita memiliki pengetahuan tentang penyakit Diabetes Melitus yang baik sebelum diberikan intervensi. 
pendelegasian dan lainnya (Muafi, 2008). Tetapi sebenarnya organisasi lebih dari itu. Organisasi juga memiliki kepribadian, persis seperti individu; bisa kaku atau fleksibel, tidak ramah atau justru mendukung, inovatif atau konservatif (Robins, 2008).

Muafi (2008) juga menyebutkan bahwa dalam organisasi juga akan mencakup budaya atau nilai dan keyakinan, serta norma yang telah diyakini keberadaannya dan diwarisi dari satu generasi ke generasi berikutnya meskipun anggota kelompoknya sudah berubah. Nilai-nilai dan keyakinan organisasi inilah yang merupakan dasar budaya organisasi (Kreitner dan Kinicki 2005). Pada tingkatan yang lebih dalam dan kurang terlihat, budaya organisasi ini akan mempengaruhi sikap dan perilaku pada orang-orang yang ada didalamnya (Muafi, 2008). Kreitner dan Kinicki (2005) menambahkan bahwa aspek budaya organisasi atau nilai-nilai dan keyakinan ini cenderung berlangsung dalam waktu yang lama dan lebih tahan terhadap perubahan. Robins (2008) juga menyatakan bahwa budaya organisasi terdiri dari karakteristik yang relatif stabil. Budaya itu dikembangkan dari tahun ke tahun dan berakar pada nilai yang kuat diyakini karyawan sehingga mendapatkan komitmen yang kuat.

Secara teori budaya organisasi adalah sejumlah pemahaman penting, seperti norma, nilai, sikap, dan keyakinan, yang dimiliki bersama oleh anggota organisasi (Stoner dkk, 1996). Robins, 2008 juga mengemukakan bahwa budaya organisasi mengacu ke sistem makna bersama yang dianut oleh anggota-anggota yang membedakan organisasi itu dari organisasiorganisasi lain. Pemahaman tentang budaya organisasi ini tumbuh dan berkembang dari pengakuan bahwa budaya organisasi akan dapat memiliki pengaruh yang signifikan bagi kesuksesan organisasi jangka pendek dan jangka panjang. Jika ada kesesuaian antara budaya dan tipe strategi bersaing maka semakin dapat meningkatkan kinerja organisasi (Muafi, 2008).

Robins (2008) menyebutkan dalam studi riset terbaru yang dilakukan oleh perusahaan consulting menemukan bahwa perusahaan yang memperkenalkan spiritualitas berdasar pada yang mampu meningkatkan produktifitas dan sangat mengurangi keluar masuknnya karyawan. Lebih lanjut Robins juga melaporkan bahwa spiritualitas dalam organisasi berhubungan positif dengan kreatifitas, kepuasan karyawan, kinerja tim, dan komitmen organisasi. Jadi budaya organisasi yang kuat memiliki dampak bagi organisasi terkait dalam hal peningkatan produktifitas, menguatkan komitmen para anggota dan menurunkan angka turnover para anggotanya. Kekuatan budaya dalam sebuah organisasi dapat terlihat dari sejauh mana para anggota dapat menerima dan menunjukkan komitmen yang kuat pada nilai-nilai dan keyakinan organisasi.

Permasalahan dalam lingkup organisasi kerja dan organisasi yang sering terjadi adalah tunrover dan absenteeism, sehingga salah satu aspek yang penting dalam organisasi adalah mempertahankan keberadaan dan menekan turnover. Untuk mempertahankan keberadaan dan menekan turnover ini, organisasi dituntut harus mampu membentuk nilai-nilai, kepercayaan dan komitmen diantara setiap pekerja terhadap organisasi (Burdayat, 2009).

Sebuah penelitian yang dilakukan Restuningdiah (2009) yang dilakukan pada beberapa akuntan pendidik juga menyebutkan bahwa komitmen profesional berpengaruh terhadap kepuasan kerja melalui komitmen organisasional. Adanya pengaruh tidak langsung ini memiliki makna bahwa seorang akutan pendidik yang memiliki loyalitas terhadap profesinya akan memiliki loyalitas pula terhadap organisasinya, sehingga hal ini menyebabkan meningkatnya kepuasan kerja. Hasil penelitian ini juga menunjukkan bahwa komitmen organisasional merupakan variabel moderator yang memperkuat pengaruh komitmen profesional terhadap kepuasan kerja. 
Penelitian sejenis juga dilakukan oleh Dewi dan Amilin (2008) yang dalam hasil penelitiannya disebutkan bahwa faktor yang mempengaruhi kepuasan kerja akuntan publik adalah komitmen organisasi. Karsono (2008) dalam penelitiannya juga mengemukakan bahwa komitmen organisasi berpengaruh positif terhadap kinerja, motivasi dan kepuasan kerja. Hal ini menjelaskan bahwa betapa pentingnya suatu organisasi dapat menumbuhkan komitmen diantara karyawan-karyawan yang ada didalamnya.

Suatu organisasi dimana para pekerjanya dipandang dan diperlakukan sebagai seorang anggota keluarga besar organisasi, akan merupakan dorongan yang sangat kuat untuk meningkatkan komitmen organisasi. Pada gilirannya komitmen organisasi yang tinggi akan berakibat pada berbagai sikap dan perilaku positif, seperti misalnya menghindari tindakan, perilaku dan sikap yang merugikan nama baik organisasi, kesetiaan kepada pimpinan, kepada rekan setingkat dan kepada bawahan, produktivitas yang tinggi, kesediaan menyelesaikan konflik melalui musyawarah dan sebagainya (Hasanbasri, 2007.

Ada beberapa alasan mengapa organisasi harus melakukan berbagai usaha untuk meningkatkan derajat komitmen organisasi dalam diri karyawan. Pertama, semakin tinggi komitmen karyawan, semakin besar pula usaha yang dilakukannya dalam melaksanakan pekerjaan. Kedua, semakin tinggi komitmen karyawan, maka semakin lama pula ia ingin tetap berada dalam organisasi. Dengan kata lain, jika karyawan mempunyai komitmen organisasi yang tinggi, maka ia tidak berniat meninggalkan organisasi dan memandang pekerjaaan bukan sebagai beban atau kewajiban tetapi sarana berkarya dan mengembangkan diri. Sehingga Karyawan yang memiliki komitmen yang tinggi pada organisasi cenderung lebih stabil dan produktif serta lebih menguntungkan organisasi dan hal ini akan berpengaruh secara langsung terhadap kualitas pelayanan dan kepuasan pasien sebagai pengguna jasa. Penulis juga melakukan wawancara dengan staff bagian kepegawaian pada tanggal 03 Mei 2011. Hasil wawancara tersebut di dapat bahwa dalam jangka waktu satu tahun terahir terdapat dua karyawan yang dikeluarkan, tiga karyawan mengundurkan diri dan lima karyawan pensiun serta ada sepuluh karyawan yang masuk. Sistem kerja bagi karyawan baru yaitu kontrak selama dua tahun yang setiap enam bulan sekali diadakan evaluasi penilaian kinerja karyawan. Jika pada saat evaluasi ternyata kinerja karyawan tersebut kurang baik maka akan dikeluarkan walaupun kontraknya belum habis.

Di rumah sakit PKU Muhammadiyah Yogyakarta juga ada kegiatan bagi karyawan yaitu pengajian rutin setiap hari rabu dan sabtu. Hal ini merupakan salah satu bagian budaya organisasi yang bersifat spiritual. Robins (2008) menyebutkan bahwa spiritualitas dalam organisasi berhubungan positif dengan kreatifitas, kepuasan karyawan, kinerja tim, dan komitmen organisasi. Di rumah sakit juga ada budaya reward bagi karyawan dengan masa kerja 15, 20, 25 dan 30 tahun yang biasanya diberikan pada acara milad rumah sakit. Hal-hal diatas merupakan bagian dari budaya organisasi yang ada di rumah sakit yang harus diikuti oleh semua karyawan yang ada di dalamnya. Jika nilai- nilai yang ada dalam organisasi tersebut tidak sesuai dengan nilai-nilai diri setiap karyawan yang bekerja di rumah sakit maka komitmen karyawan terhadap organisasi juga akan rendah. Karena karyawan belum merasa memiliki keterikatan dan kesamaan dengan organisasi tempat bekerja. Berdasarkan keterangan dari staff bagian kepegawaian juga dinyatakan juga bahwa mayoritas perawat di bagian rawat inap kelas II dan III memiliki masa kerja diatas lima tahun. Hal ini terlihat bahwa perawat di bagian rawat inap kelas II dan III memiliki loyalitas yang cukup tinggi pada organisasi. Berdasarkan latar belakang tersebut maka penulis ingin meneliti tentang hubungan budaya 
Latar belakang pendidikan orang tua pun perlu diperhatikan, karena terkadang hal ini dapat mempengaruhi pengetahuan tentang gizi seorang anak. Orang tua merupakan pendidik yang pertama dan utama bagi anakanak mereka. Tanggung jawab ibu dalam keluarga adalah membimbing anak, dimulai sejak masih dalam kandungan. Pengetahuan tentang tumbuh kembang anak selayaknya harus dimiliki seorang ibu, seperti pemberian ASI, perhatian tentang asupan gizi, pemberian pendidikan, cinta kasih dan lain lain (Supriyadi, 2006).

Petugas kesehatan juga salah satu sumber informasi yang pernah memberikan informasi terkait tentang gizi pada 3 orang responden $(10 \%)$. Informasi tentang gizi secara umum maupun khusus memang paling tepat apabila dilakukan oleh petugas kesehatan, terlebih mereka telah ahli dibidangnya dalam menanggapi masalah khas tentang gizi pada anak dan mampu memberikan konseling untuk orang tua dan anak-anak yang berkaitan dengan masalah gizi. Penyuluhan gizi menjadi landasan terjadinya perubahan pengetahuan, sikap dan keterampilan. Kelembagaan penyuluhan gizi seperti Posyandu perlu lebih diperkuat sehingga aktivitas penyuluhan tidak terabaikan (Khomsan, 2006). Hal yang sama juga telah disampaikan pada penelitian Sukandar (2008) yang menyatakan metode penyuluhan dengan Materi pengetahuan gizi dasar mencakup jenis-jenis pangan sumber zat tenaga, sumber zat pembangun, sumber zat pengatur serta fungsi, akibat kekurangan, akibat kelebihan dari karbohidrat, protein, vitamin dan mineral dapat meningkatkan pengetahuan gizi. Diharapkan dengan meningkatnya pengetahuan gizi akan meningkatkan kesadaran responden akan pentingnya zat gizi yang terkandung dalam makanan untuk memperbaiki status gizi mereka. Peningkatan pengetahuan gizi juga dapat mengurangi kepercayaan akan tabu makanan yang merugikan gizi dan kesehatan responden.

\section{2) Tingkat Pengetahuan Gizi Pada Siswa Kelas 5 SD Muhammadiyah Dadapan Sesudah Diberikan Buku Saku}

Berdasarkan penelitian ini telah didapatkan bahwasanya media sangat berperan penting dalam peningkatan pengetahuan gizi pada anak. Fungsi media dalam pendidikan adalah sebagai alat peraga untuk menyampaikan informasi atau pesan pesan tentang kesehatan (Notoatmodjo, 2003). Responden mengaku belum pernah mendapatkan informasi tetang gizi melalui media cetak seperti buku, majalah, surat kabar, atau jenis media cetak yang lainnya, sehingga peneliti mencoba memberikan informasi tentang gizi melalui media cetak. Media yang digunakan adalah media cetak berupa buku saku. Buku saku yang diberikan berisi tentang materi gizi seimbang yang didukung oleh gambar dengan ukuran $11 \times 8 \mathrm{~cm}$. Buku saku merupakan buku dengan ukuran kecil seukuran saku sehingga efektif untuk di bawa kemana mana dan dapat dibaca kapan saja pada saat dibutuhkan, dengan keefektifan buku saku tersebut siswa dapat memperoleh pengetahuan mengenai gizi.

Media cetak merupakan media yang paling dekat dengan siswa. Materi cetak juga menempati posisi penting dalam pendidikan kesehatan karena 
memberikan pesan jelas yang dapat dibawa kerumah. Materi itu efektif dalam memperkuat informasi yang disampaikan secara lisan ataupun bila memang digunakan sebagai media untuk menyampaikan informasi itu sendiri (Bensley dan Fisher, 2009).

Media digunakan dalam kegiatan pembelajaran karena memiliki kemampuan untuk (1) menyajikan peristiwa yang kompleks dan rumit menjadi lebih sistematik dan sederhana, (2) meningkatkan daya tarik dan perhatian pembelajar dan (3) meningkatkan sistematika pembelajaran (Hasyim, 2008).

3) Pengaruh Buku Saku Terhadap Tingkat Pengetahuan Gizi Pada Anak Kelas 5 SD Muhammadiyah Dadapan Desa Wonokerto Kecamatan Turi Kabupaten Sleman Yogyakarta

Penelitian ini bertujuan untuk mengetahui pengaruh buku saku gizi terhadap tingkat pengetahuan gizi pada anak Kelas 5 Sekolah Dasar, dengan alasan bahwa anak kelas 5 Sekolah Dasar telah memasuki masa remaja sehingga pengetahuan tentang gizi sangat penting sekali diberikan agar siswa dapat memenuhi kebutuhan gizi secara seimbang guna mengoptimalkan pertumbuhan fisik, psikologis dan perkembangan kognitif yang sempurna. Buku saku diberikan kepada anak dengan harapan dapat memperbaiki tingkat pengetahuan gizi pada anak sehingga anak dapat memperbaiki perilaku makan yang salah, untuk mencegah penyakit yang ditimbulkan oleh kekurangan gizi dan meningkatkan kesadaran responden tentang pentingnya konsumsi makanan yang bergizi seimbang.

Pada analisis mean menunjukkan nilai perbedaan rata rata sebelum dengan sesudah pemberian buku saku yaitu -19.733 . Nilai Signifikan Sig (2 -tailed) $(0.000)<0.025$ dan Confidence interval $95 \%-22,820<1>-16,646$ (tidak mencakup angka 1). Artinya buku saku tentang Gizi memberikan pengaruh terhadap pengetahuan gizi anak kelas 5 SD Muhammadiyah Dadapan Di Desa Wonokerto Kecamatan Turi Kabupaten Sleman Yogyakarta. Hal ini dikarenakan buku saku yang diberikan telah didesain untuk anak-anak. Materi dan istilah-istilah tentang penyakit yang disebabkan oleh kekurangan gizi yang dimuat dalam buku saku menggunakan kata kata yang sederhana, selain itu buku saku juga berisi gambar gambar seperti nyata sehingga responden dapat membaca sekaligus melihat contoh makanan yang bergizi dan penyakit penyakit yang disebabkan karena kekurangan gizi melalui gambar. Materi buku saku juga memuat contoh dalam bentuk cerita pendek agar responden lebih dapat memahami dan mengerti hubungan antara informasi yang diperoleh mereka dengan masalah mereka sendiri. Menurut Rapiasih, Dkk, (2010) Pancaindera menentukan berapa banyak informasi yang diserap jika melibatkan mata, telinga disertai diskusi, latihan dan penggunaan, maka informasi akan terserap $90 \%$. Hal yang sama juga didapatkan pada penelitian Reppie (2007) yang mendapati bahwa konseling gizi dengan buku saku dapat mempengaruhi penurunan asam urat darah dan asupan purin. Persamaan ini juga dimungkinkan karena faktor pendidikan, pendidikan dapat mempengaruhi pola pikir seseorang termasuk dalam memanfaatkan informasi tentang gizi. 


\section{SIMPULAN DAN SARAN}

\section{A. Simpulan}

1) Siswa Kelas 5 Sekolah Dasar Muhammadiyah Dadapan sebagian besar memiliki tingkat pengetahuan gizi yang baik pada saat sebelum diberikan buku saku yaitu sebanyak 18 orang $(60 \%)$ dari 30 orang Siswa.

2) Siswa Kelas 5 Sekolah Dasar Muhammadiyah Dadapan semuanya memiliki tingkat pengetahuan gizi yang baik pada saat sesudah diberikan buku saku yaitu sebanyak 30 orang (100\%) dari 30 orang Siswa.

3) Ada perbedaan tingkat pengetahuan gizi antara sebelum (pre test) dan sesudah (post test) diberikan buku saku gizi dengan nilai mean sebelum diberikan buku saku 71,33 dan mean sesudah diberikan buku saku 91,07 Artinya ada pengaruh Buku Saku Gizi terhadap tingkat pengetahuan gizi pada anak kelas 5 Sekolah Dasar Muhammadiyah Dadapan Desa Wonokerto Kecamatan Turi Kabupaten Sleman Yogyakarta.

B. Saran

1) Pendidikan gizi secara umum dan khusus seharusnya sejak dini diberikan pada anak usia Sekolah Dasar, agar dapat dijadikan salah satu cara untuk meningkatkan pengetahuan, sikap dan perilaku konsumsi makan anak sekolah, karena anak usia sekolah merupakan kelompok yang rentan terhadap penyakit yang disebabkan kekurangan gizi dan merupakan kelompok yang strategi dalam upaya perubahan perilaku terhadap gizi dan kesehatan di masa depan terutama untuk masyarakat yang tinggal di Daerah Pedesaan atau terpencil.

2) Penggunakan media dapat menjadi masukan bagi para guru dan Sekolah dalam meningkatkan pengetahuan gizi pada anak Sekolah.

3) Perlu adanya penelitian lebih lanjut bukan hanya untuk meningkatkan pengetahuan saja melainkan meningkatkan sikap dan perilaku masyarakat terkait tentang gizi

\section{DAFTAR PUSTAKA}

1. Ahmadi, Dedy., 2010, Efektivitas Penyuluhan Terhadap Pola Konsumsi Jajanan Anak Sekolah yang Mengandung Pemanis Buatan di SD Negri No.2 Lhoksukon Kabupaten Aceh Utara, Tesis, Universitas Sumatera Utara, Medan.

2. Almatsier, Sunita., 2003, Prinsip Dasar IImu Gizi, Gramedia Pustaka, Jakarta

3. Dewi, Anita,L. Arrofi, Sumi. Setya, Angga, Erwin., 2011, Peningkatan Pengetahuan Gizi Anak Usia Sekolah Melalui Pengoptimalan Pendidikan Jasmani Dan Kesehatan (Penjaskes) Menggunakan Media Ular Tangga, Institut Pertanian Bogor.

4. Evi. Hasim, 2008. Penggunaan Media Kata Bergambar Dalam Upaya Meningkatkan Kualitas Pembelajaran Membaca dan Menulis Permulaan di Kelas I Sekolah Dasar, Jurnal penelitian dan pendidikan, Vol 5 No.2 hal 78-87 
5. Karunia, 2009, Pengaruh Konseling Gizi Dengan Buklet Dan Lealet Terhadap Pengetahuan, Sikap, Perilaku, Dan Asupan Zat Gizi Pasien Dialisis Peritoneal Mandiri Berkeinambungan (DPMB) di RSUD Dr. Sarjito, Skripsi, Universitas Gajah Mada.

6. Khomsan, Ali. Anwar, Faisal. Sukandar, Dadang, Riyadi, Hadi. Mudjajanto, Eddy, S., Studi Tentang Pengetahuan Gizi Ibu Dan Kebiasaan Makan Pada Rumah Tangga Di Daerah Dataran Tinggi Dan Pantai, Jurnal gizi dan pangan, Juli 20061 (1): 23-28

7. Mulyati. Tatik, Prawirohartono, E,P. Sudargo, Toto, 2004, Pengaruh Pendidikan Gizi Kepada ibu Terhadap Konsumsi Makanan Dan Statusgizi Anak Balita Penderita Tuberkulosis Primer Di Rawatjalan Rsup Dr. Kariadi Semarang. Jurnal Gizi Klinik Indonesia,Volume 1 No.2

8. Niryati, S., 2010, Pentingnya Pendidikan Gizi Bagi Anak, http:// usesaefurohman.wordpres.com/2010/01/25/pentingnyapendidikangizibagianak, diambil tangagal 5 maret 2011

9. Priyanto, Ibnu., 2006, Hubungan Tingkat Pengetahuan Gizi Seimbang Dengan Status Gizi Remaja Pada Siswa Siswi Madrasah Aliyah Negri Wonokromo Kabupaten Bantul, Skripsi, Universitas Ahmad Dahlan.

10. Proverawati, A, Asfuah, S., 2009, Buku ajar Gizi Untuk Kebidanan. Media Pustaka. Yogyakarta.

11. Proverawati, A, Erna., 2010. IImu Gizi Untuk Keperawatan Dan Gizi Kesehatan. Media pustaka, Yogyakarta

12. Rapiasih, N,Wayan. Prawiningdyah, Yeni. Lestari, Lily, A,. 2010, Pelatihan Hygiene Sanitasi Dan Poster Berpengaruh Terhadap Pengetahuan, Perilaku Penjamah Makanan, Dan Kelaikan Hygiene Sanitasi Di Instalasi Gizi RSUP Sanglah Denpasar, Jurnal Gizi Klinik Indonesia Vol. 7, No. 2: 64-73.

13. Sugiyono, 2010, Statistik Untuk Penelitian, CV Alfabeta, Bandung

14. Suciptawati, Niluh,. 2009, Metode Statistika Nonparametik, Udayana Universiti Press. Denpasar

15. Suhardjo, 2003, Berbagai Cara Pendidikan Gizi, Bumi Aksara, Jakarta.

16. Susanto, N., 2008, Hubungan Pengetahuan Ibu Tentang Gizi Dengan Praktek Ibu Dengan Praktek Pemberian Makanan Bergizi Pada Anak Usia 1-3 Tahun Di Kelurahan Margosari Pengasih Kulon Progo, Skripsi, Universitas Ahmad Dahlan.

17. Supriyadi, 2007, Peran Orang Tua Terhadap Pertumbuhan dan Perkembangan anak, Jurnal Penelitian No. 1855 Vol.:30

18. Suiraoka, I,Putu. Supardi, Suharyanto. Dewi, Tetra, F,S. 2004. Perancangan Media Promosi Kesehatan GAKI Pada Anak SD di Daerah Endemik di Provinsi Bali, Jurnal Penelitian Berita Kedokteran No.2 Vol XX

19. Sukandar. Dadang, 2008., Jawa Barat. Makanan Tabu di Rokan Hulu Riau, Departemen Gizi Masyarakat, Jawa Barat.

20. Syarief, hidayat., 2010, Masalah Gizi di IndonesiaKondisi Gizi Masyarakat Memprihatinkan, http://www.gizi.net/cgibin/berita/fullnews.cgi?newsid1088142057,65767, diambil pada tanggal 5 maret 2011.

21. Syafinah, Wahyuni TD., 2010, Pengaruh Buku Saku Sebagai Media Konsultasi Gizi Terhadap Penurunan Kadar Gula Darah Anggota Persadia Kota Yogyakarta, Skripsi, Universitas Ahmad Dahlan.

22. Thamrin, M, Husni, 2007, Pemberian Makanan Tambahan Untuk Meningktakan Kemampuan Mengikuti Pelajaran Pada Siswa Sekolah Dasar, Jurnal Kependidikan, Jurnal Kependidikan XXXVII No. 1

23. Yusuf, Syamsul., 2010, Psikologi Perkembangan Anak Dan Remaja. PT Remaja Rosdakarya. Bandung

24. Yuliana, Khomsan. Ali, Patmonodewo. Soemiarti, Riyadi. Hadi, Muchtadi. Deddy, Pengaruh Penyuluhan Gizi-Kesehatan Dan Faktor Lainnya Terhadap Pertumbuhan Anak Usia Prasekolah. Jumal Gizi dan Pangan dan Gizi, November 2006 1(2):8-16 